\title{
Perancangan film animasi 3D nikmatnya sholat tahajud menggunakan metode pose-to-pose
}

\author{
Nada Nadhira Najwa Mazaya ${ }^{\mathrm{a}, 1, *}$, Juniardi Nur Fadila ${ }^{\mathrm{b}, 2}$, Fresy Nugroho ${ }^{\mathrm{b}, 3}$ \\ aJurusan Teknik Informatika, Fakultas Sains dan Teknologi, Universitas Islam Negeri Maulana Malik Ibrahim Malang, Indonesia \\ ${ }^{1} 19650040 @$ student..uin-malang.ac.id*; ${ }^{2}$ juniardi.nur@uin-malang.ac.id; ${ }^{3}$ fresy@ti.uin-malang.ac.id
}

\section{ABSTRACT}

Animasi 3D bernuansa islami sudah mulai berkembang pesat di Indonesia. Hal ini memang benar adanya jika sudah mulai tersebar dan semakin populer di berbagai aplikasi media sosial. Hal tersebut menjadi pemicu kenaikan popularitas dari Animasi 3D terutama yang bernuansa islami. Pembuatan animasi 3D secara keseluruhan menggunakan komputer dan terdiri dari beberapa tahap yakni modelling, texturing/material, ringing, dan rendering, yang mana semuanya dilakukan secara digital pada software Blender. Metode yang digunakan adalah "Pose-to-Pose", yaitu metode yang mengutamakan dengan membuat gerakan kunci atau key pose sehingga dapat membuat gerakan akan lebih halus. Film animasi 3D ini dirancang dengan tujuan untuk mengedukasi dan menginformasikan tentang kenikmatan sholat tahajud. Tak hanya itu, animasi 3D ini juga menceritakan betapa pentingnya peran orang tua di kehidupan anaknya. Perancangan film animasi 3D yang dibuat diharapkan dapat menghasilkan sebuah film animasi yang dapat mengedukasi dan pastinya dapat mengetahui pesan moral yang telah disajikan.

\section{Pendahuluan}

Seiring perkembangan teknologi yang semakin maju, tentunya akan lebih banyak teknologi yang muncul. Salah satu contohnya adalah video animasi 3 dimensi atau 3D. Video animasi adalah teknologi pembuatan gambar bergerak dengan cara menampilkan objek tidak bergerak dalam sejumlah sekuens secara cepat sehingga menimbulkan kesan bergerak. Dalam perkembangannya, muncul berbagai alat dan teknologi yang memungkinkan gambar-gambar seolah-olah bergerak, mulai dari alat sederhana berbentuk seperti silinder yang dipasangi serangkaian gambar dan diputar sehingga menimbulkan efek bergerak hingga munculnya teknologi sinematografi yang mulai memakai proyektor, printer dan kamera [1].

Di Indonesia, kini tren teknologi animasi semakin positif dan telah berkembang yang ditandai dengan banyaknya karya anak bangsa yang merajai produksi film-film animasi khusus anak-anak dan keluarga. Industri animasi sebenarnya merupakan tren yang menjanjikan di masa depan, apalagi dengan pemakaian internet yang meningkat secara tajam. Video animasi bisa dipakai untuk berbagai kebutuhan mulai dari film, iklan komersial, video klip, hingga media pembelajaran yang bisa diunggah secara mandiri melalui berbagai platform. Penelitian [2] mengemukakan bahwa penggunaan animasi dalam proses pembelajaran sangat membantu dalam meningkatkan efektifitas dan efisiensi proses pengajaran, serta hasil pembelajaran yang meningkat. Selain itu, penggunaan media pembelajaran khususnya animasi dapat meningkatkan daya tarik, serta motivasi siswa dalam mengikuti proses pembelajaran.

Dalam dunia animasi, apapun menjadi sangat mungkin. Kemajuan teknologi membuat film animasi menjadi lebih sempurna dan luwes dalam bertutur. Tumbuhnya film animasi untuk segala kaum tak lepas dari pengaruh eksplorasi dari banyak animator yang ingin menampilkan sesuatu yang berbeda [3]. Didukung dengan latar belakang masyarakat Indonesia yang mayoritas memeluk agama 
Islam, peneliti bermaksud memanfaatkan video animasi untuk merancang sebuah film animasi 3D mengenai nikmatnya sholat tajahud. Melalui film animasi 3D ini peneliti akan membuat bahan ajar yang dibuat visualiasi ke dalam bentuk gambar animasi yang lebih bermakna dan menarik, serta memotivasi penontonnya yang mayoritas adalah anak-anak. Hal ini juga akan sangat membantu para orang tua sebagai sosok yang mempunyai peran penting dalam kehidupan anaknya melalui mengajarkan ilmu agama dan penerapannya untuk anak-anaknya.

Perancangan film animasi 3D nikmatnya sholat tahajud tersebut menggunakan metode pose-topose. Pose-to-pose merupakan metode penggambaran secara tidak berurutan atau meloncat-loncat. Penggambaran dilakukan pada pose awal dan pose akhir kemudian baru menggambar pose diantaranya, kemudian antar pose dan pose akhir, serta pose awal disisipi gambar di antaranya lagi, begitu seterusnya[4].

Pembuatan animasi 3D terdiri dari tiga tahapan besar yakni tahap pra produksi, tahap produksi, dan tahap pasca produksi[5]. Pada tahapan tersebut juga terdapat proses-proses yang harus dilakukan mulai dari penentuan alur cerita, karakter, hingga riset komponen film. Dalam pembuatan animasi 3D juga terdapat berbagai metode yang dapat digunakan. Metode yang digunakan untuk membuat film animasi 3D pada penelitian ini adalah metode pose-to-pose, yang merupakan salah satu metode proses animating yang telah lama dikenal [6]. Metode pose-to-pose merupakan sebuah metode dimana animator merencanakan seluruh gerakan dalam animasi dan menentukan pose kunci atau keypose dari setiap gerakan tersebut[7]. Pada metode pose-to-pose, pose-pose kunci yang akan dilakukan oleh tokoh atau karakter pada suatu adegan ditentukan terlebih dahulu. Setelah pose kunci tersebut ditentukan, barulah kemudian gerakan pada pose-pose yang ada digabungkan dengan cara menyisipkan pose diantara dua pose [8]. Tahapan yang dilakukan pada metode ini yakni menentukan gerakan keyframe, ekstreme, dan inbetween [9].

Software yang digunakan untuk membuat film animasi 3D pada penelitian ini adalah Blender 2.8. Software Blender memiliki berbagai fitur yang dapat digunakan. Fitur-fitur tersebut antara lain pemodelan 3D, unwarpping $U V$, texturing, rigging dan skinning, fluid and smoke simulation, particle simulation, animating, match moving, camera tracking, rendering, video editing, dan compositing [10]. Ada tiga dasar yang digunakan pada software Blender, yakni vertice (titik), edge (garis), dan face (bidang). Manipulasi dari ketiga dasar tersebutlah yang kemudian akan dapat membentuk sebuah objek tiga dimensi.

\section{Metode Riset}

Secara umum, proses pembuatan animasi 3D dikategorikan menjadi tahap pra-produksi (preproduction) sebagai tahap awal, produksi (production) sebagai tahap kedua, dan pasca-produksi (post-production) sebagai tahap akhir proses pembuatan animasi 3D[11]. Masing-masing tahapan tersebut terbagi lagi menjadi beberapa unsur yang akan dijelaskan lebih rinci sebagai berikut. 


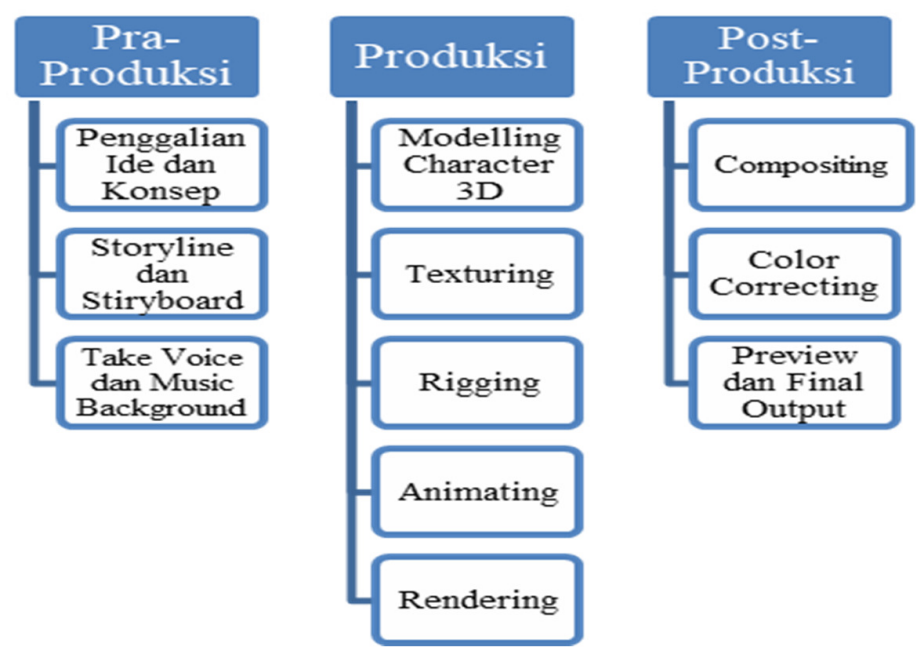

Gambar 1. Metode Riset

\subsection{Pra-Produksi}

Tahap pre-production atau pra-produksi sebagai proses awal (persiapan) dalam pembuatan suatu animasi 3D mencakup beberapa unsur diantaranya penggalian ide dan konsep, storyline dan storyboard, serta take voice dan music background yang akan dijelaskan sebagai berikut [11]. Pada tahap pra-produksi ini kita akan menentukan desain karakter yang akan dibuat, mulai dari sketsa sederhana, sampai visualisai awal yang disertai rancangan warna yang digunakan. Hasil dari tahap pra-produksi akan digunakan sebagai pegangan dalam modelling karakter pada tahap produksi [12].

\subsubsection{Penggalian Ide dan Konsep}

Proses penggalian ide dan konsep serta gagasan untuk animasi yang akan dibuat bisa datang dari berbagai hal seperti kisah klasik, kisah nyata, legenda, dongeng, fantasi/fiksi, dan lain-lain. Hal yang terpenting adalah selalu kreatif dalam mencari dan mengolah serta mengembangkan ide tersebut. Ide dan konsep dibentuk berdasarkan tujuan sekaligus sebagai motivasi yang bisa datang dari individu pribadi atau pihak lain. Ide harus memiliki keistimewaan, keunggulan, dan keunikan yang khas sehingga menarik untuk diangkat sebagai tema animasi 3D[11]. Penentuan ide cerita merupakan proses pertama yang harus dilakukan dalam pembuatan film animasi 3D. Proses ini sangat penting untuk dilakukan, karena ide cerita merupakan awal dari alur cerita keseluruhan yang akan dibuat[13].

\subsubsection{Storyline dan Storyboard}

Storyline sebagai inti dari sebuah naskah yang diambil dari gagasan utama naskah tersebut yang dibuat seperti alur cerita (gagasan penting dalam naskah tersebut). Sedangkan storyboard sebagai bentuk visual/gambar dari skenario yang telah dibuat berupa kotak-kotak gambar (layaknya membuat komik) guna menggambarkan jalan cerita dan adegan-adegan yang hendak dibuat dalam film tersebut.

Pembuatan storyboard merupakan proses yang sangat penting dalam perancangan film animasi 3D. Storyboard sendiri merupakan sebuah alat penerjemah berupa gambar berdasarkan naskah atau skenario yang telah dibuat sebelumnya[14]. Storyboard juga dapat diartikan sebagai serangkaian sketsa yang menggambarkan urutan elemen aplikasi multimedia, yang menggabungkan narasi dan visual pada selembar kertas[15]. Pada proses ini naskah yang telah dibuat dikembangkan menjadi sederetan gambar yang berurutan, yang berfungsi untuk gambaran dasar dari film animasi yang akan dibuat.

\subsubsection{Take Voice dan Music Background}

Proses tahap ini identik dengan proses pengambilan dan perekaman suara untuk mengisi suara karakter animasi. Karena pada dasarnya take voice menjadi proses dalam mendapatkan 
sound (suara) yang dibutuhkan dengan cara melakukan rekaman langsung dari objek karakter yang bersangkutan.

\subsection{Produksi}

Terdapat beberapa hal yang berhubungan dengan proses produksi dalam pembuatan suatu animasi 3D yang mencakup beberapa unsur diantaranya modelling character 3D, texturing, rigging, dan rendering yang akan dijelaskan sebagai berikut.Proses tahap ini identik dengan proses pengambilan dan perekaman suara untuk mengisi suara karakter animasi. Karena pada dasarnya take voice menjadi proses dalam mendapatkan sound (suara) yang dibutuhkan dengan cara melakukan rekaman langsung dari objek karakter yang bersangkutan [11].

\subsubsection{Modelling Character 3D}

Modelling charater 3D identik dengan penyusunan bentuk objek yang menggunakan basis 3 dimensi yang merupakan pengembangan dari 2 dimensi, dimana objek disusun dari point, edge, dan polygon hingga terbentuklah sebuah objek 3D yang diinginkan. Model bisa berupa karakter (makhluk hidup) seperti manusia, hewan, atau tumbuhan; atau berupa benda mati, seperti rumah, mobil peralatan, dan lain-lain. Model harus dibuat dengan mendetail dan sesuai dengan ukuran dan skala pada sketsa desain/model yang telah ditentukan sebelumnya sehingga objek model akan tampak ideal dan proporsional untuk dilihat[11].

\subsubsection{Texturing}

Proses texturing identik dengan proses pembuatan ataupun pemberian warna dan texture (material) pada objek yang telah dimodelkan sebelumnya sehingga menampilkan suatu kesan yang nyata. Proses ini merupakan proses dimana objek diberi karakteristik berupa warna dan tekstur[16]. Disamping itu juga bisa menggunakan bantuan perangkat lunak digital imaging seperti Photopaint, Photoshop, atau GMIP. Texturing ini menentukan karakteristik sebuah materi obyek dari segi tekstur. Untuk materi sebuah objek bisa digunakan aplikasi properti tertentu seperti reflectivity, transparency, dan refraction [17].

\subsubsection{Rigging}

Rigging merupakan sebuah proses pemberian struktur kerangka atau tulang pada suatu objek karakter[18]. Rigging merupakan hal yang penting dan bila terjadi sesuatu pada animasi kita berarti itu adalah kesalahan pada saat rigging. Meskipun kemungkinan besar itu merupakan kesalahan proses modelling dimana objek 3D tersebut tidak sesuai topologi pada umumnya sehingga mengakibatkan peyok. Jadi jika ada tangan atau siku berbentuk balok itu adalah kesalahan rigging atau kesalahan modelling.

Sebuah rig karakter pada dasarnya adalah sebuah kerangka digital terikat mesh 3D, seperti tengkorak yang nyata, rig terdiri dari sendi dan tulang, yang masing-masing bertindak untuk "menangani" yang animator dapat gunakan untuk menekuk karakter tersebut ke dalam pose yang diinginkan. Rig ini menggantikan fungsi tulang dalam dunia nyata. Namun rig tidak terbatas pada karakter manusia tapi bisa diset sedemikian rupa untuk kebutuhan motorik. Rigging juga bisa digunakan untuk mobil, mesin, dan semua pergerakan yang otomatis.

\subsubsection{Animating}

Animating identik dengan proses pembuatan animasi untuk model dalam bentuk gerakan objek atau gerakan kamera guna menciptakan animasi walktought, flythrough, dan lain-lain. Pada tahap ini, karakter sudah melewati tahap modelling, texturing, dan rigging akhirnya bisa digerakkan untuk animasinya. Tahap animating biasanya dimulai dari blocking animation untuk membuat key pose atau pose-pose utama karakter tersebut. Panduan gerakan tetap berpacu pada storyboard dan animator bisa melakukan sedikit improvisasi pada arah gerakan karakter yang disesuaikan dengan storyboard pada tahap pra-produksi [11].

\subsubsection{Rendering}

Rendering sebagai tahap akhir dari keseluruhan proses pemodelan ataupun animasi komputer. Dalam rendering, semua data-data yang sudah disiapkan dalam proses modelling, 
animasi, texturing, pencahayaan dengan parameter tertentu akan diterjemahkan dalam sebuah bentuk output sebagai tampilan akhir pada model dan animasi yang dikerjakan[18]. Tujuan utamanya adalah menjadikan animasi yang sudah diedit menjadi sebuah video yang bisa dijalankan semua software pemutar video. Proses rendering dalam pengkalkulasian model 3D yang telah diberikan efek texture, rigging, animation, dan lain-lain. Dengan demikian, hasil animasi yang didapatkan menjadi tampak sangat nyata dan menarik.

Rendering harus dilakukan secara cermat dan teliti, sehingga ada kalanya dilakukan prerendering sebelum prosedur rendering yang sesungguhnya dilaksanakan. Dengan selesainya tahap rendering, akhirnya tahap produksi animasi akan diikuti oleh masuknya tahap postproduksi, yaitu tahap di mana hasil produksi akan memasuki tahap finalisasi akhir untuk kemudian diberikan koreksi warna dan pemasukan audionya [11].

\subsection{Post-Produksi}

Tahap pasca produksi atau post-produksi merupakan akhir dari keseluruhan proses dasar pembuatan animasi 3D dan merupakan tahap penyempurna dari tahapan-tahapan sebelumnya. Pada tahap ini menugaskan animator dalam menambahkan modifikasi akhir seperti halnya diberikan koreksi warna dan pemasukan audionya sehingga film animasi lebih. Beberapa komponen yang dapat dilakukan pada produk animasi 3D, diantaranya sebagai berikut.

\subsubsection{Compositting}

Tahap compositing sangat mempengaruhi durasi film beserta scene di dalamnya, karena pada tahap ini sangat membutuhkan keterampilan dalam video editing baik dalam konteks memotong scene/cuplikan yang tidak dibutuhkan dan menggabungkan scene-scene yang terdapat di dalam animasi yang sedang dibuat. Dalam proses ini sering terjadi penambahan transisi video yang selalu diaplikasikan.

\subsubsection{Color Correcting}

Color correcting menjadi poin penting dalam tahap pasca produksi, sebab proses ini mampu mengubah panorama film sesuai kebutuhan. Misalnya, menggunakan beberapa efek warna untuk diaplikasikan ke film animasi yang sedang dibuat, diantaranya Color Corrector, Color Channel, RGB Settings, Hue/Saturation, dan lainnya.

\subsubsection{Preview dan Final Output}

Tahap ini merupakan tahap penyatuan keseluruhan animasi, audio, dan compositing yang telah dibuat sebelumnya. Hasil akhir telah dikemas menggunakan berbagai media penyimpanan digital apapun seperti CD atau DVD dan selanjutnya akan didistribusikan kepada pemirsa yang merupakan target komunikasi dari produk video tersebut. Pengemasan hasil akhir bertujuan agar kelak dapat digandakan atau didistribusikan secara masal[11].

\section{Hasil dan Pembahasan}

Film animasi ini berjudul "Nikmatnya Sholat Tahajud" terdiri dari 2 karakter, kedua karakter Ayah dan Nada yang sedang berdialog tentang kenikmatan sholat tahajud dengan latar belakang ruang tamu dan kamar tidur yang terdapat kursi, tv, ac, meja, kasur, komputer dan properti lainnya.

\subsection{Pra Produksi}

Tahap pra iproduksi imerupakan tahapan sebelum animasi diproses pada aplikasi Blender. Tahap ini berisi tahap menentukan cerita yang akan dibuat animasi

\subsubsection{Ide Cerita}

Ide cerita merupakan hal yang penting dalam proses pembuatan animasi. Ide cerita yang saya buat merupakan suatu nasehat dari Ayah untuk Nada tentang kenikmatan sholat tahajud. 
"Nah, sekarang Ayah ingin memberi sesuatu, Insyaallah mempermudah kamu nak. Jadi gini, pada $\mathrm{Al}$ - Qur'an surah $\mathrm{Al}$ - Isra' ayat 79, Wa minal laili fatahajjad bihii naafilatal laka 'asaaa any yab'asaka Rabbuka Maqoomam Mahmuudaa. Jadi nak, Allah SWT memerintahkan Rasulullah dan umatnya agar bangun di malam hari untuk mengerjakan sholat Tahajud. Dan ada riwayat juga, Rasulullah SAW pernah ditanya orang, 'Salat manakah yang paling utama setelah sholat yang diwajibkan (sholat lima waktu)?' Rasulullah SAW menjawab, 'Sholat

\subsubsection{Storyboard}

1. Scene yang menunjukkan Nada sedang mempunyai banyak angan, ia sedang berkhayal di malam hari

2. Scene yang menunjukkan Nada dihampiri Ayahnya saat merenung

3. Scene yang menunjukkan Ayah sedang mendengarkan keluh kesah angan Nada

4. Scene yang menunjukkan Ayah membangunkan Nada untuk melaksanakan Sholat Tahajud

5. Scene yang menunjukkan Ayah menjelaskan betapa nikmatnya Sholat Tahajud itu

6. Scene yang menunjukkan Nada bersemangat untuk melaksanakan Sholat Tahajaud

\subsection{Produksi}

Proses ini adalah proses yang seluruhnya di kerjakan dalma aplikasi 3D blender. Tahapan-tahapan yang di kerjakan adalah sebagai berikut.

\subsubsection{Proses Modelling}

Proses ini merupakan proses pembuatan latar, asset, dan juga karakter atau tokoh. Pembuatan karakter 3D digunakan dengan menggunakan objek primitif yaitu uvspahere dan plane [19]. Objek plane digunakan saat pembuatan bagian tubuh sedangkan uvspahere digunakan ketika membuat bola mata.

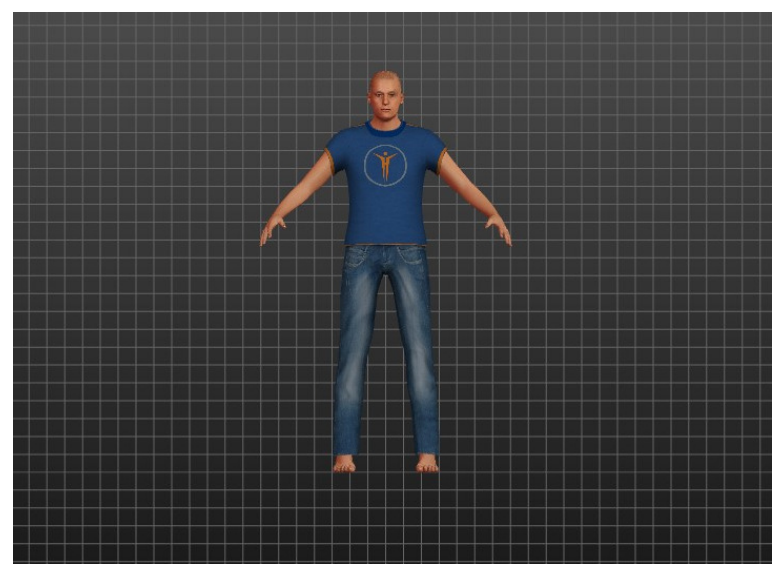

Gambar 2. Proses Modelling

\section{Gambar Modeling karakter}

Proses pembuatan latar dan aset banyak menggunakan objek dasar seperti cylinder, plane, dan cube diatur panjang, pendek, lebar, dan volumenya untuk mendapatkan hasil yang di inginkan. Dasaran dalam membuatnya lebih terarah menggunakan modifier subdivision surface karena dengan adanya itu diharapkan mendapatkan ketajaman dan kesimetrisan yang baik dan tepat dari asset yang dibuat.

\subsubsection{Proses Teksturing}

Proses ini memberikan sebuah tekstur atau karakteristik sebuah benda dan objek. Hal ini akan menentukan bagaimana karakteristik suatu objek yang akan dibuat dengan 
mengaplikasikan transparency, refraction, dan reflectivity. Hasil yang sudah di dapat nantinya akan mempengaruhi bariasi pola warna yang ada.

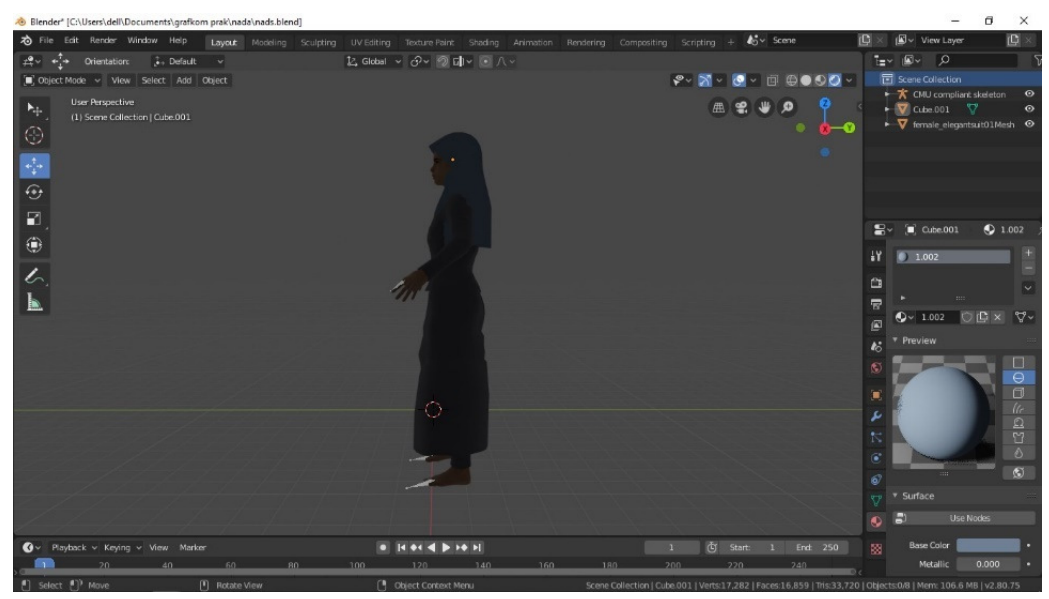

Gambar 3 Proses Teksturing

\subsubsection{Proses Rigging}

Rigging adalah pemberian armature pada sebuah object karakter. Setiap karakter yang akan di gerakan wajib memberikan armature yang bertujuan untuk mendapatkan derakan yang dinamis saat proses animating. Selain itu, rigging juga bisa digunakan untuk kontrol atau penggerkan setiap sendi dan bagian tubuh setiap karakter. Armature sendiri dikelompokkan menjadi 3 sesuai dengan fungsinya, antara lain bone untuk menggerakkan bagian kepala, menggerakkan mulut, menggerakkan tangan dan kaki dan menggerakkan pinggul.

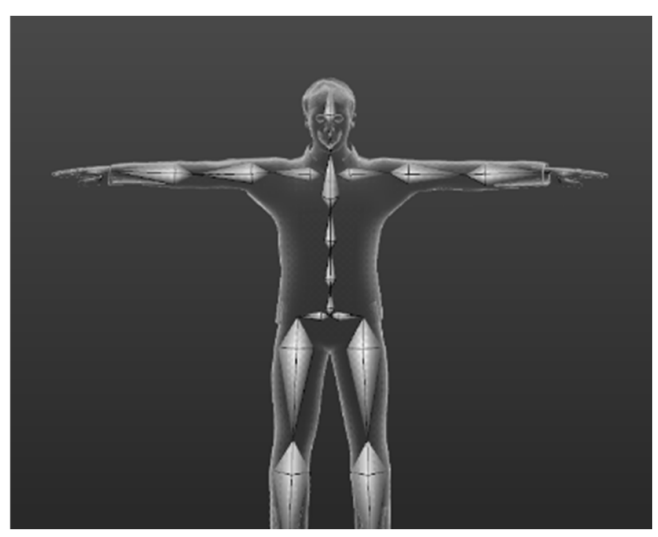

Gambar 4. Proses Rigging

\subsubsection{Penyatuan Objek - Objek}

File-file objek karakter, latar dan asset atau properti 3D yang telah di buat sebelumnya akan di satukan menjadi satu file jadi yang bertujuan untuk membuat sebuah scene cerita yang lengkap dan utuh. 


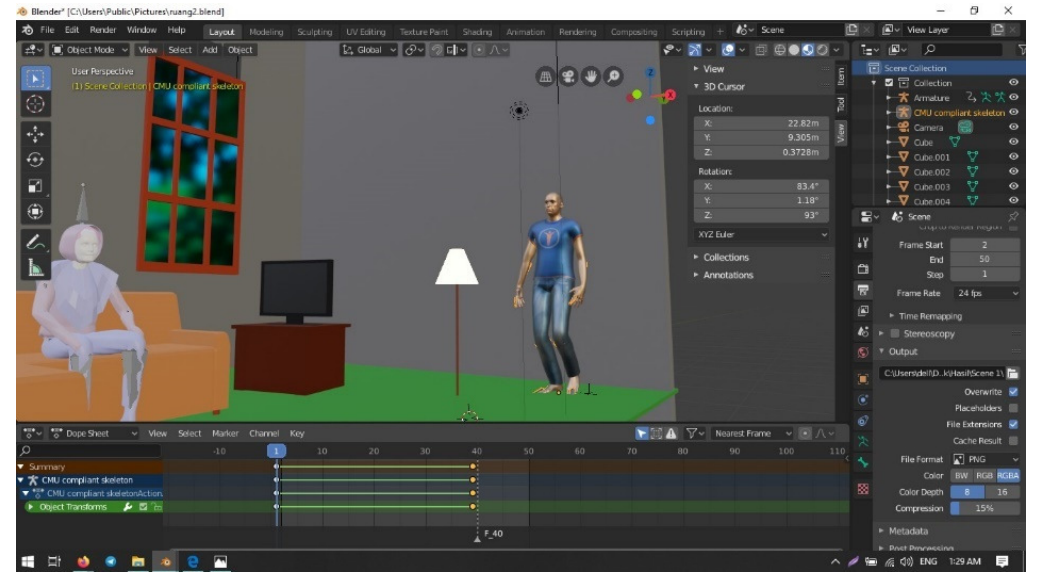

Gambar 5. Proses Penyatuan Objek

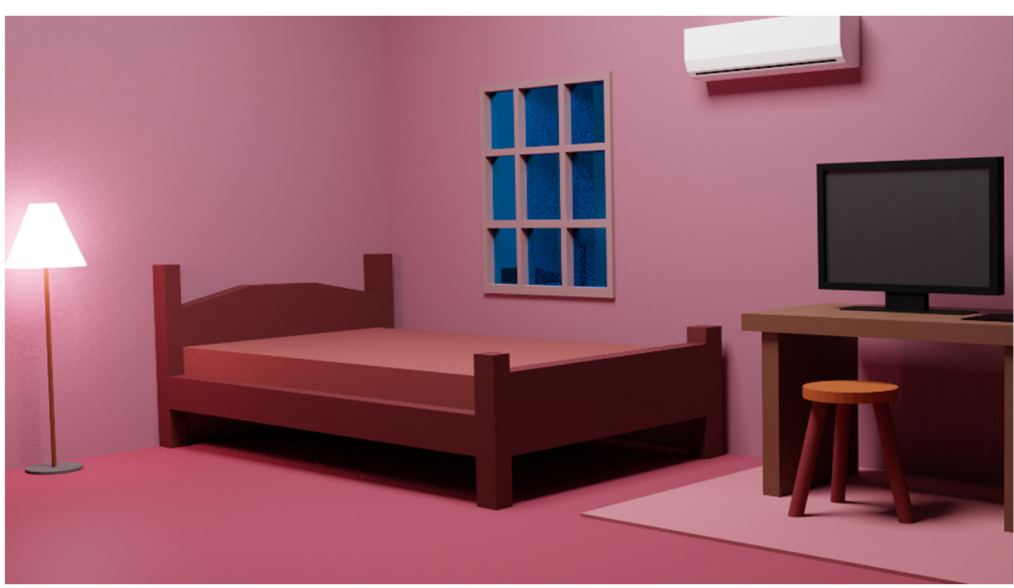

Gambar 6. Hasil Penyatuan Objek

\subsubsection{Animating}

Animating adalah sebuah proses penggerakan karakter yang sudah di buat, berbeda dengan rigging yang hanya memberikan titik-titik, di dalam animating karakter akan di gerakkan sesuai dengan alur cerita yang ada. Window yang digunakan dalam proses animating ini adalah action editor. Proses ini sangat penting untuk nantinya dapat mempraktekkan metode Pose to Pose karena terdapat fitur yang berguna untuk mementukan dimana key frame diletakkan. Proses ini juga proses dimana penggunaan loc rot scale yang bertujuan untuk mengunci lokasi, rotasi serta ukuran bagian yang akan digerakkan.

Pada proses ini akan dilakukan juga penataan kamera dan staging objek dan krakter yang telah di satukan dalam satu file. Penataan ini akan sangat berpacu pada scenario yang telah dibuat. Tampilan animasi yang terdapat pada software Blender mempunyai beberapa bagian, antara lain yaitu dopesheet, timeline, dan viewer. Hal pokok yang harus diperhatikan adalah mengatur pose objek karakter dari rigging yang telah dibuat kemudian insert key frame untuk menguncinya.

\section{Kesimpulan}

Film animasi 3D ini bertemakan islam yang menceritakan tentang seorang Ayah dan anaknya bernama Nada yang berdialog mengenai kenikmatan sholat Tahajud agar semua permasalahan tidak 
terasa berat dan juga tidak menimbulkan rasa was - was di dalam hati. Animasi ini dimulaidari membuaa storyboard sampai rendering animasi yang siap di publish. Hasil animasi ini dirancang

dalam bertuk video berdurasi 70 detik yang di dalamnya menggunakan metode Pose-to-Pose. Metode ini menghasilkan perrgerakan animasi yang lebih halus. Penggunaan metode Pose-to-Pose ini sangat membantu dalam kelancaran pembuatan animasi berjudul Nikmatnya Sholat Tahajud.

\section{Ucapan Terima Kasih}

Pada penelitian ini, penulis mengucapkan terima kasih kepada dosen mata kuliah Grafika Komputer yaitu bapak Fressy Nugroho, M.T dan bapak Juniardi Nur Fadila, M.T yang telah berkontribusi pada penelitian ini dan membimbing dalam proses penelitian yang telah dilakukan.

\section{Daftar Pustaka}

[1] Fitria, Rahmi. (2013, 24 Agustus). Teknologi Animasi, Industri Kreatif yang Menjanjikan. Retrieved from https://www.kompasiana.com/rahmifitria.

[2] Mayer, R. E. \& Moreno, R. (2002). Animation as an Aid Multimedia Learning. educational psychology review, Vol. 14, No.1, March 2002. Diakses dari http://search.proquest.com pada tanggal 3 Juni 2021.

[3] Dunia Film Animasi. (2020). Jakarta: Tempo Publishing.

[4] Mardi. (2020). Cara Mudah Membuat Animasi. Sidoarjo: Zifatama Jawara.

[5] Zebua, T., Nadeak, B., \& Sinaga, S. B. (2020). Pengenalan Dasar Aplikasi Blender 3D dalam Pembuatan Animasi 3D. Jurnal ABDIMAS Budi Darma, 1(1), 18-21.

[6] Affandi, Y., Satia Nuryanto, N., Mahendra, E., \& Eka Setiawan, S. (2019). Implementasi Metode Pose to Pose dalam Pembuatan Animasi 2D Gerakan Ruku' Shalat. Respati, 14(1), 12-16. http://jit.respati.ac.id/index.php/jurnaljti/article/view/265.

[7] Salmon, S. F., Tulenan, V., \& A. Sugiarso, B. (2017). Penggunaan Metode Pose to Pose dalam Pembuatan Animasi 3D Tarian Minahasa Maengket. Jurnal Teknik Informatika, 12(1), 1-9. https://doi.org/10.35793/jti.12.1.2017.17867.

[8] Lazimi, S. (2018). Animate Karakter Dalam Produksi Film Animasi 3D “Mira Diwana ” Menggunakan Teknik Pose To Pose. Institut Bisnis dan Informatika STIKOM Surabaya

[9] Purwanto, I. H., Qodarsih, L., Majid, F. H., \& Syamrahmarini, K. A. (2019). Implementasi Pose To Pose Pada Simulasi Gerak Panda Berjalan Dengan Teknik Frame By Frame. Explore, 9(1), 43. https://doi.org/10.35200/explore.v9i1.164.

[10] Aslah, T. Y., Wowor, H. F., \& Tulenan, V. (2017). Perancangan Animasi 3D Objek Wisata Museum Budaya Watu Pinawetengan. Jurnal Teknik Informatika, 11(1). https://doi.org/10.35793/jti.11.1.2017.16922.

[11] Asmoro, Siwi Widi, \& Joko Pramono. (2019). Animasi 2D dan 3D SMK/MAK Kelas XI, Kompetensi Keahlian Multimedia, Program Keahlian Teknik Komputer dan Informatika. Yogyakarta: ANDI.

[12] Ramadhan, Arief, \& Favorisen R. Lumbanraja. (2006). Karakter dan Animasi 3D dengan 3D Studio Max 7. Jakarta: ElexMedia.

[13] Cynthia Margareth Silalahi, Fera Damayanti, D. (2020). PERANCANGAN DESIGN INTERIOR RUMAH DENGAN MENGGUNAKAN APLIKASI BLENDER. SNASTIKOM, 143-151

[14] Syafrizal, A., Toyib, R., \& Saputra, G. (2019). Pembuatan Animasi 3D Profil Fakultas Teknik Universitas Muhammadiyah Bengkulu. 20, 24-25.

[15] Amin, A. (2016). PEMBUATAN FILM ANIMASI CARA UMRAH SESUAI SOFTWARE BLENDER. In Teknologi pendidikan. UIN Maulana Malik Ibrahim Malang.

[16] Hera, M. W., \& Syahminan, M. P. T. S. (2020). RANCANGAN ANIMASI 3D WISATA EMBUNG WALAN MENGGUNAKAN PROSES PENDEKATAN USER REQUIREMENT. Kurawal Jurnal Teknologi, Informasi Dan Industri, 3(1), 66-80. 
[17] Nurcahyono, Nugroho. (2018). Teknik Animasi dan 2D dan 3D untuk SMK/MAK Kelas XI. Jakarta: PT Gramedia Widiasarana Indonesia.

[18] Ainiyah, K., Hidayah, N., Damayanti, F. P., Hidayah, I. N., Fadila, J. N., \& Nugroho, F. (2020). Rancang Bangun Film Animasi 3D Sejarah Terbentuknya Kerajaan Samudra Pasai Menggunakan Software Blender. JISKA (Jurnal Informatika Sunan Kalijaga), 5(3), 164-176. https://doi.org/10.14421/jiska.2020.53-04

[19] Aslah, T. Y., Wowor, H. F., \& Tulenan, V. (2017). Perancangan Animasi 3D Objek Wisata Museum Budaya Watu Pinawetengan. Jurnal Teknik Informatika, 11(1). https://doi.org/10.35793/jti.11.1.2017.16922.

[20] Caroline, Y., Tulenan, V., \& Sugiarso, B. A. (2016). Rancang Bangun Film Animasi 3 Dimensi 